\title{
A MEDIATION MODEL TO EXPLAIN THE ROLE OF MATHEMATICS SKILLS AND PROBABILISTIC REASONING ON STATISTICS ACHIEVEMENT
}

\author{
CATERINA PRIMI \\ Neurofarba - Section of Psychology \\ University of Florence - Italy \\ caterina.primi@unifi.it \\ MARIA ANNA DONATI \\ Neurofarba - Section of Psychology \\ University of Florence - Italy \\ mariaanna.donati@unifi.it \\ FRANCESCA CHIESI \\ Neurofarba - Section of Psychology \\ University of Florence - Italy \\ francesca.chiesi@unifi.it
}

\begin{abstract}
Among the wide range of factors related to the acquisition of statistical knowledge, competence in basic mathematics, including basic probability, has received much attention. In this study, a mediation model was estimated to derive the total, direct, and indirect effects of mathematical competence on statistics achievement taking into account probabilistic reasoning ability. The participants were psychology students enrolled in an undergraduate introductory statistics course. At the beginning of the course, all students completed a questionnaire to measure their proficiency in the basic probabilistic reasoning and mathematics skills required in introductory statistics courses. At the end of the course, the students' final grades were collected. The hypothesized mediation model was tested using a bootstrapping procedure (with 5000 bootstrap samples). Results showed a significant positive, indirect effect of mathematical competence on students' final grades, with probabilistic reasoning ability acting as a mediator. This study suggests that interventions designed to promote the mathematical prerequisites necessary to probabilistic reasoning can have a positive effect on achievement in statistics.
\end{abstract}

Keywords: Statistics education research; Probabilistic reasoning; Statistics achievement; Mathematics skills; Mediation model

\section{INTRODUCTION}

Statistics education should enable students to interpret and critically evaluate statistical information, understand data-related arguments, build intuition about data, and make reasoned judgments and decisions: in other words, to become reflective, engaged and constructive citizens (Gal, 2003; Rumsey, 2002; Utts, 2003). Indeed, the ability to think

Statistics Education Research Journal, 15(2), 169-178, http://iase-web.org/Publications.php?p=SERJ

(C) International Association for Statistical Education (IASE/ISI), November, 2016 
critically about uncertain outcomes and to make decisions on the basis of probabilistic information is valuable in many fields (e.g., business, medicine, politics, law). In contrast, the inability to determine optimal choices based on given information can be extremely costly, not only at the individual level, but also for society in general. For this reason, statistics has been incorporated into a wide range of university programs around the world. Unfortunately, it is commonly viewed by students as a difficult and unpleasant topic, and statistics courses as a stressful and anxiety-inducing burden. As statistics courses are compulsory in many programs, the consequences of failing these courses can be very serious: Some students may be forced to abandon their academic and professional aspirations, contributing to the drop-out rate for these university programs.

From an educational perspective, it is crucial to develop students' statistical reasoning and to provide them with tools and knowledge for understanding and using quantitative information (Utts, 2003). That is, the main challenge in teaching and learning statistics is to ensure that students not only acquire the mechanics of statistical methods, but also the concepts that underlie statistical reasoning (Garfield, 2003; Garfield \& Ben-Zvi, 2008). To attain this goal, it is essential to identify variables that weaken or enhance statistical reasoning and to determine the nature of barriers faced by students in developing such reasoning.

In line with this goal, prior research (e.g., Budé et al., 2007; Chiesi \& Primi, 2010; Dempster \& McCorry, 2009) has proposed models which describe the process of learning statistics as a result of the interplay between several factors. The influence of affect, or students' attitude towards statistics, is one of the factors that has been considered. Specifically, studies have shown that students' achievement in statistics courses may be directly or indirectly related to their perception of the difficulty of the domain of statistics, their beliefs about whether they possess the knowledge and ability needed to learn statistics, their positive and negative feelings about statistics, and their perception of the value of statistics (e.g., Tempelaar, van Der Loeff \& Gijselaers, 2007; Tremblay, Gardner, \& Heipel, 2000; Nasser, 2004). In particular, some research has shown that positive attitudes are associated with better exam results (Vanhoof et al., 2006). The negative impact of statistics anxiety on performance has also been widely studied (see, e.g., Onwuegbuzie, 2003; Onwuegbuzie \& Wilson, 2003; Vigil-Colet, Lorenzo-Seva, \& Condon, 2008), and the literature on statistics anxiety provides evidence that it may impair learning and performance by interfering with students' ability to concentrate on and encode statistical concepts. In extreme cases, students who experience high levels of statistics anxiety find it so difficult to complete statistics exams that they delay the completion of their degree program, or in some cases, fail to complete it (Fitzgerald, Jurs, \& Hudson, 1996; Macher, Paecheter, Papousek, \& Ruggeri, 2011).

Other studies have addressed the importance of mathematics skills for achievement in statistics courses (Chiesi \& Primi, 2010; Harlow, Burkholder, \& Morrow, 2002; Schutz, Drogozs, White, \& Distefano, 1998). Results of tests designed to measure competency in basic mathematics skills have demonstrated that students with low mathematical competency obtain significantly lower grades in introductory statistics courses than students with medium to high competency (Galli, Chiesi \& Primi, 2011; Johnson \& Kuennen, 2006). This does not mean that statistics achievement depends solely on basic mathematical abilities, but the research does suggest that they are a necessary tool which facilitates the understanding of certain foundational statistical concepts. For example, the basic mathematical skill of understanding ratios may be important in understanding and interpreting standard deviation measures, whether the computation is done by hand or by software packages (Johnson \& Kuennen, 2006; Lunsford \& Poplin, 2011). In addition, students who have mastered the relevant basic mathematics skills are also more likely to 
perceive the subject of statistics as being accessible and useful and less likely to experience anxiety in statistics courses. In short, regardless of the amount of computation required, basic mathematics skills are important determinants of students' success in statistics courses.

Finally, some authors (Garfield, 2005; Konold \& Kazak, 2008) suggested that some of the difficulties encountered by the students in learning basic data analysis stem from a lack of basic understanding of probability. Indeed, it has been widely documented (see Chernoff \& Sriraman, 2014 for a review) that people commonly hold misconceptions about probabilistic concepts and ideas, and, as a consequence, some prevalent ways of thinking about statistical inference are inconsistent with a correct understanding of these concepts. Among several explanations, Garfield and Ahlgren (1988) pointed out that one of the reasons that students have difficulties in grasping the fundamental ideas of probability may be that they have underlying difficulties with the concepts of rational numbers, decimals, and percentages - in other words, with basic mathematics skills.

With the above research as background, in this study we investigated the relationship between mathematics skills and achievement in statistics, examining the role of probability knowledge in particular. In other words, we hypothesized that success in learning statistics would be associated with students' mastery of basic mathematics skills, but we also conjectured that probabilistic reasoning in particular may be a significant predictor of achievement in this area. In order to discern the role of probabilistic reasoning, a mediation model was estimated to determine the total, direct, and indirect effects of mathematical competence on achievement in statistics taking into account probabilistic reasoning ability. We hypothesized that basic mathematics skills support students' understanding of basic concepts of probability and, consequently, enhance the learning of concepts in statistics. That is, we hypothesized that when students are more proficient in computing and interpreting percentages, in working with rational numbers, and in engaging in proportional reasoning, they are able to solve probability problems more easily. As a consequence, these students are more likely to grasp ideas about the likelihood of samples and samples of data, to make predictions about data and random events, to understand the fundamentals of hypothesis testing, and to properly interpret conclusions derived from statistical testing.

\section{METHOD}

\subsection{PARTICIPANTS}

The participants in this study were 124 psychology students (mean age $=20.14$; SD = 2.2) enrolled in an undergraduate introductory statistics course at the University of Florence in Italy. The course was compulsory for first year students. It ran for ten weeks and consisted of a weekly 4-hour lecture and 2-hour tutorial (where students worked in groups). Classes were structured around the discussion of theoretical issues, followed by practical examples and pen and paper exercises. The majority of the participants were women (85\%). This proportion reflects the gender distribution of the population of psychology students in Italy. All students participated on a voluntary basis.

\subsection{MATERIALS}

Probabilistic Reasoning Questionnaire (PRQ; Primi, Morsanyi, \& Chiesi, 2014) This questionnaire included 16 multiple-choice probabilistic reasoning tasks (one correct answer among three alternatives). Items included simple, conditional, and conjunctive probabilities, and data were presented both as frequencies and as percentages (e.g., "A ball 
was drawn from a bag containing 10 red, 30 white, 20 blue, and 15 yellow balls. What is the probability that it is neither red nor blue? a. $30 / 75$; b. $10 / 75$; c. $45 / 75$ "; and " $60 \%$ of the population in a city are men and $40 \%$ are women. $50 \%$ of the men and $30 \%$ of the women smoke. We select a person from the city at random. What is the probability that this person is a smoker? a. $42 \%$, b. $50 \%$, c. $85 \%$ "). A single composite score was computed based on the sum of correct responses. Cronbach's alpha coefficient for the sample in this study was determined to be 0.70 .

Mathematics Prerequisites for Psychometrics (MPP; Galli et al, 2011) This test was developed with the aim of assessing the mathematics skills needed by students enrolling in introductory statistics courses. The content was determined on the basis of the mathematics needed to solve descriptive and inferential statistics problems. The concepts assessed included, among others, the basics of arithmetic, which are employed in both descriptive and inferential statistics tasks (e.g., to compute the standard deviation, as well as t or $\mathrm{z}$ values); the basics of set theory (including the concepts of inclusion-exclusion and intersection), which are required for representing and understanding probability rules and concepts; and first order equations, which are used, for instance, in standardization procedures and in regression analysis. Additional items addressed the interpretation of relations (i.e., less than, greater than, equal to) between numbers that range from 0 to 1 and numbers expressed as absolute values. This competence was deemed necessary for hypothesis testing (e.g., to compare the computed and the critical values to decide whether the null hypothesis should be accepted or rejected). Item response theory analyses were applied in constructing the test, and its reliability and validity were tested. The test consists of 30 problems and is in multiple-choice format (one correct answer among four alternatives). A single composite based on the sum of correct responses was calculated. Cronbach's alpha for the current sample in this study was determined to be 0.80 .

Measure of achievement The participants' achievement was measured by the final examination grade, which was assigned according to a rubric designed by the course instructor. The final examination consisted of a written task and an oral exam. The written task consisted of six problems (to be solved by paper-and-pencil procedure, without the support of a statistics computer package) and four conceptual open-ended questions (e.g., defining the null hypothesis in hypothesis testing). The problems involved computing descriptive indices for a data matrix (3-4 variables, 10-12 cases), reporting data in a twoway table or by graphing, as well as choosing and applying appropriate statistical tests (identifying the null and the alternative hypotheses, finding the critical value, calculating the value of a test, and making a decision regarding the level of significance). Marks (ranging from 0 to 30) of 18 and above were considered to be satisfactory. Students who scored 18 or higher on the exam were admitted to the oral exam. The oral exam provided the students with an opportunity to improve their performance (from 0 to 3 points). They were asked to comment on the mistakes they had made on the written exam and/or to complete questions that were incomplete or partially incomplete. The final grade-which took into account both the written and verbal portions of the exam—ranged from 18 to 30, in accordance with the Italian University Grading System.

\subsection{PROCEDURE}

At the beginning of the course, all students were administered the PRQ and the MPP to measure, respectively, their basic probabilistic reasoning and mathematics skills. The participants completed the two tests individually in the classroom. Each task was briefly 
introduced, and instructions for completion were given. The average total completion time was 30 minutes. The final written examination at the end of the course was timed (2 hours) and followed by the oral examination. Finally, the students' final grades were collected.

\subsection{STATISTICAL ANALYSIS}

To investigate our hypothesis about the relationships between mathematics skills, probabilistic reasoning ability, and achievement, we computed Pearson correlations among these variables.

To further enhance understanding of the mechanisms underlying relationships among these variables, a mediation model was tested. Mediation implies a situation where the effect of the independent variable $(\mathrm{X})$ on the dependent variable $(\mathrm{Y})$ can be explained by a third variable $(\mathrm{M})$, called a mediator, which is caused by the independent variable and is itself a cause for the dependent variable. By modeling an intermediate variable, the overall effect between $\mathrm{X}$ and $\mathrm{Y}$ can be decomposed into component parts, called the direct effect of $\mathrm{X}$ on $\mathrm{Y}$ and the indirect effect of $\mathrm{X}$ on $\mathrm{Y}$ through $\mathrm{M}$ (i.e., the mediated effect).

The INDIRECT macro for SPSS (Hayes, 2013) was used, which tested the hypothesized model using a bootstrapping procedure (with 5000 bootstrap samples) to estimate the 95\% confidence interval for the indirect (mediated) effect (for more details, see Preacher \& Hayes, 2008). Bootstrapping is a resampling strategy for estimation and hypothesis testing. With the bootstrapping method, the sample is conceptualized as a pseudo-population that represents the broader population from which the sample was derived, and the sampling distribution of any statistic can be generated by calculating the statistic of interest in multiple resamples from the dataset. The bootstrapping procedure has been suggested as representing the most trustworthy test for assessing the effects of mediation models, overcoming issues associated with inaccurate p-values that result from violations of parametric assumptions (Hayes \& Scharkow, 2013). Indeed, the bootstrapping procedure is advantageous because it does not impose the assumption of normality of the sampling distribution of indirect effects, and it maintains high power while maintaining adequate control over Type I error rate (Hayes, 2009; MacKinnon, Lockwood, Hoffman, West \& Sheets, 2002; MacKinnon, Lockwood \& Williams, 2004; Preacher \& Hayes, 2008). The bootstrap test is statistically significant (at .05) if both confidence limits have the same sign (e.g., both positive or both negative). This indicates that zero is not a likely value, and therefore, that the null hypothesis of the indirect effect being zero should be rejected.

\section{RESULTS}

As Table 1 shows, mathematics skills and probabilistic reasoning ability were both significantly positively correlated with achievement. It was also found that mathematics skills were significantly positively correlated with probabilistic reasoning.

To gain a better understanding of the mechanism underlying the relationships among these variables, the hypothesis that probabilistic reasoning mediates the effect of mathematics skills on achievement in statistics was tested. This procedure allows us to analyze if the independent variable influences the dependent variable directly (path c' in Figure 1) and indirectly (ab in Figure 1) through the mediator. The direct and indirect effects add to yield the total effect (c in Figure 1) of the independent variable on the dependent variable. The mediation model was estimated to derive the total, direct, and indirect effects of mathematics skills on achievement through probabilistic reasoning. The indirect effect of mathematics skills on achievement was estimated, quantified as the 
product of the ordinary least squares (OLS) regression coefficient estimating probabilistic reasoning ability from mathematics skills (i.e., Path a in Figure 1) and the OLS regression coefficient estimating achievement from probabilistic reasoning ability controlling for mathematics skills (i.e., Path b in Figure 1).

Table 1. Correlations between achievement, mathematics skills, and probabilistic reasoning, and descriptive statistics for each measure

\begin{tabular}{llll}
\hline & 1 & 2 & 3 \\
\hline 1. Achievement & - & & \\
2. Mathematics skills & $0.34^{* * *}$ & - & \\
3. Probabilistic reasoning & $0.30^{* *}$ & $0.59 * * *$ & - \\
\hline $\mathrm{M}$ & 24.8 & 24.1 & 13.2 \\
$(\mathrm{SD})$ & $(3.8)$ & $(3.8)$ & $(2.4)$ \\
\hline$* * * p<.001 ; * * p<.01$ & & & \\
\hline
\end{tabular}

As shown in Figure 1, results indicated a significant total effect of mathematics skills on achievement $(t=3.45,95 \% \mathrm{CI}=0.128$ to $0.472, p<0.01)$, while the direct effect was found to be non-significant ( $p=0.16$ ). Moreover, a significant positive indirect effect of mathematics skills on achievement through probabilistic reasoning was found. Indeed, the bias-corrected bootstrap 95\% CI for the product of these paths (ab) did not include zero (point estimate $=0.15,95 \%$ CI $=0.048$ to 0.297 . Kappa squared was 0.126 (95\% CI $=$ 0.043 to 0.227 ), indicating a medium effect size for the indirect effect (Preacher \& Kelley, 2011).

Thus, the results indicated that mathematical skills predicted achievement. Nevertheless, once the effect of probabilistic reasoning was taken into account, the effect of mathematics skills was no longer significant. In fact, an indirect effect of mathematics skills on statistics achievement through probabilistic reasoning has been found. In sum, the results indicated that the effect of mathematics skills on the achievement was mediated by probabilistic reasoning among this sample of students.

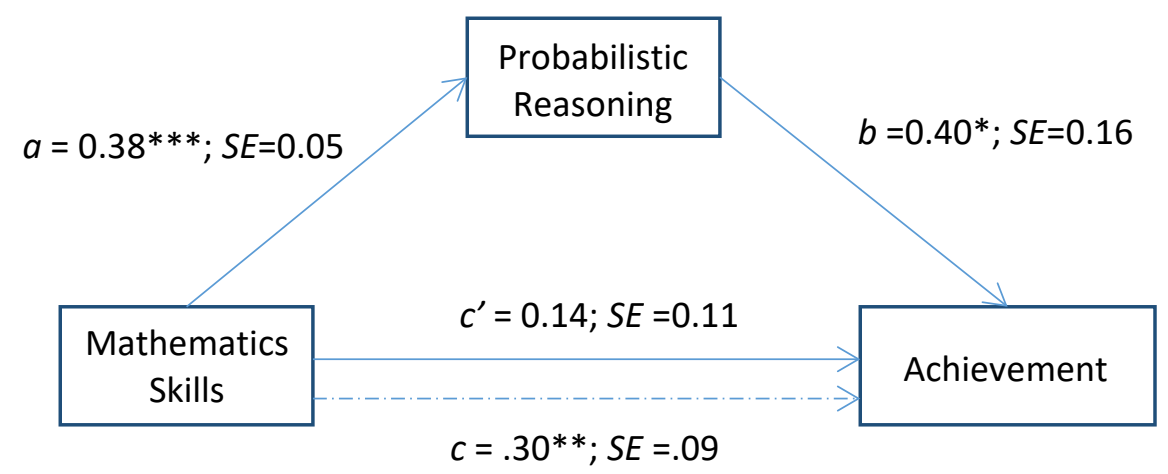

Figure 1. Path coefficients for mediation analysis on achievement; $a, b, c$, and c' are unstandardized ordinary least squares (OLS) regression coefficients

$$
{ }^{*} p<0.05 ;{ }^{* *} p<0.01 ;{ }^{* * *} p<0.001
$$

\section{DISCUSSION}

Statistical literacy supports people in making informed choices in a wide range of situations in the everyday life, such as choosing between investment options, assessing the 
incidence rates for health problems, or voting for new policies. Consequently, it is often touted as an expected outcome of schooling and a necessary component of adults' numeracy and literacy skills.

In this study, we aimed to identify the variables that weaken or enhance university students' achievement in statistics courses. Among the wide range of factors related to the acquisition of statistical knowledge, competence in basic mathematics, including basic probability, has received much attention in previous research. The aim of this study was to provide further insight into the mechanisms underlying the relationship between achievement in statistics and mathematics skills, evaluating in particular the role of probabilistic reasoning ability as a mediator.

In line with previous research (e.g., Chiesi \& Primi, 2010; Lunsford, \& Poplin, 2011; Tremblay et al., 2000), it was found that proficiency in basic mathematical skills is correlated with achievement in statistics. Moreover, our results provided evidence that probabilistic reasoning ability mediates the relationship between mathematics skills and achievement. Specifically, strong mathematics skills appear to be correlated with a better ability to reason in probabilistic terms, which in turn is correlated with higher achievement. It was found that basic mathematical skills, such as being able to work with ratios, may be important in working with concepts and problems in probability, and, in turn, the understanding of probability has a positive effect on learning statistics. These results suggest that basic mathematics skills constitute a necessary tool for learning statistics. Indeed, concepts in both probability and statistics tend to be based on straightforward combinations of basic concepts in arithmetic, algebra, and measurement; consequently, many fundamental ideas in probability and statistics become more accessible when basic mathematics skills have been mastered.

These findings (in particular, that the relationship between math skills and achievement can be explained by taking into account the mediating role of probabilistic reasoning ability) suggest that in order to promote probabilistic reasoning and, consequently, achievement in statistics, it may be useful to arrange activities at universities aimed at helping students master basic mathematics skills.

This being said, we recognize that the learning of statistics and probability does not depend only on basic mathematics knowledge, and we do not want to overstress computation at the expense of understanding how statistical studies are conducted and interpreted, or to underemphasize the need for students to be able to integrate information from study design to final conclusions in a meaningful way. However, many researchers and instructors have recently argued that there is little need to emphasize computational fluency in the learning of statistics. Moreover, given that sophisticated calculators and statistics packages can often perform most of the procedures taught in introductory statistics courses, it may be tempting to believe that numerical literacy is not important in such courses. However, as this study shows, basic mathematics skills represent a necessary tool to consolidate and foster proper reasoning and understanding in the learning of statistics.

\section{REFERENCES}

Budè, L., Van De Wiel, M. W. J., Imbos, T., Candel, M. J. J. M., Broers, N. J., \& Berger, M. P. F. (2007). Students' achievements in a statistics course in relation to motivational aspects and study behaviour. Statistics Education Research Journal, 6(1), 5-21. [Online: http://iase-web.org/documents/SERJ/SERJ6(1) Bude.pdf ] 
Chernoff, E. J., \& Sriraman, B. (Eds.). (2014). Probabilistic thinking: Presenting plural perspectives. Advances in Mathematics Education Series. Berlin/Heidelberg: Springer Science.

Chiesi, F., \& Primi, C. (2010). Cognitive and non-cognitive factors related to students' statistics achievement. Statistics Education Research Journal, 9(1), 6-26. [Online: http://iase-web.org/documents/SERJ/SERJ9(1)_Chiesi_Primi.pdf ]

Dempster, M., \& McCorry, N. K. (2009). The role of previous experience and attitudes toward statistics in statistics assessment outcomes among undergraduate psychology students. Journal of Statistics Education, 17(2).

[Online: http://ww2.amstat.org/publications/jse/v17n2/dempster.html ]

Fitzgerald, S. M., Jurs, S., \& Hudson, L. M. (1996). A model predicting statistics achievement among graduate students. College Student Journal, 30, 361-366.

Gal, I. (2003). Teaching for statistical literacy and services of statistics agencies. The American Statistician, 57(2), 80-84.

Galli, S., Chiesi, F., \& Primi, C. (2011). Measuring mathematical ability needed for "nonmathematical" majors: The construction of a scale applying IRT and differential item functioning across educational contexts. Learning and Individual Differences, 21, 392402. doi: 10.1016/j.lindif.2011.04.005

Garfield, J. (2003). Assessing statistical reasoning. Statistics Education Research Journal, 2(1), 22-38.

[Online: http://iase-web.org/documents/SERJ/SERJ2(1).pdf ]

Garfield, J. (2005). How students learn statistics. International Statistical Review, 63(1), 25-34.

Garfield, J., \& Ahlgren, A. (1988). Difficulties in learning basic concepts in probability and statistics: Implications for research. Journal for Research in Mathematics Education, 19(1), 44-63.

Garfield, J. B., \& Ben-Zvi, D. (2008). Developing students' statistical reasoning: Connecting research and teaching practice. The Netherlands: Springer.

Harlow, L. L., Burkholder, G. J., \& Morrow, J. A. (2002). Evaluating attitudes, skill, and performance in a learning-enhanced quantitative methods course: A structural modeling approach. Structural Equation Modeling, 9(3), 413-430.

Hayes, A. F. (2009). Beyond Baron and Kenny: Statistical mediation analysis in the new millennium. Communication Monographs, 76(4), 408-420. doi:10.1080/03637750903310360

Hayes, A. F. (2013). Introduction to mediation, moderation, and conditional process analysis: A regression based approach. New York, NY: Guilford Press.

Hayes, A. F., \& Scharkow, M. (2013). The relative trustworthiness of inferential tests of the indirect effect in statistical mediation analysis: Does method really matter? Psychological Science, 24, 1918-1927. doi:10.1177/0956797613480187

Johnson, M., \& Kuennen, E. (2006). Basic math skills and performance in an introductory statistics course. Journal of Statistics Education, 14(2).

[Online: http://ww2.amstat.org/publications/jse/v14n2/johnson.html ]

Konold, C., \& Kazak, S. (2008). Reconnecting data and chance. Technology Innovations in Statistics Education, 2(1).

Lunsford, M. L., \& Poplin, P. (2011). From research to practice: Basic mathematics skills and success in introductory statistics. Journal of Statistics Education, 19(1), 1-22.

[Online: http://ww2.amstat.org/publications/jse/v19n1/lunsford.pdf ]

MacKinnon, D. P., Lockwood, C. M., Hoffman, J. M., West, S. G., \& Sheets, V. (2002). A comparison of methods to test mediation and other intervening variable effects. Psychological Methods, 7, 83-104. doi:10.1037/1082-989X.7.1.83 
MacKinnon, D. P., Lockwood, C. M., \& Williams, J. (2004). Confidence limits for indirect effect: Distribution of the product and resampling methods. Multivariate Behavioral Research, 39, 99-128. doi:10.1207/s15327906mbr3901_4.

Macher, D., Paecheter, M., Papousek, I., \& Ruggeri, K. (2011). Statistics anxiety, trait anxiety, learning behavior, and academic achievement. European Journal of Psychology of Education, 27, 483-498.

[Online: http://dx.doi.org/10.1007/s10212-011-0090-5]

Nasser, F. (2004). Structural model of the effects of cognitive and affective factors on the achievement of Arabic-speaking pre-service teachers in introductory statistics. Journal of Statistics Education, 12(1).

[Online: http://ww2.amstat.org/publications/jse/v12n1/nasser.html]

Onwuegbuzie, A. J. (2003). Modeling statistics achievement among graduate students. Educational and Psychological Measurement, 63, 1020-1038.

Onwuegbuzie, A., \& Wilson, V. (2003). Statistics anxiety: Nature, etiology, antecedents, effects, and treatments - a comprehensive review of the literature. Teaching in Higher Education, 8, 195-2009. doi:10.1080/1356251032000052447

Preacher, K., \& Hayes, A. (2008). Asymptotic and resampling strategies for assessing and comparing indirect effects in multiple mediator models. Behavior Research Methods, 40, 879-891. doi:10.3758/BRM.40.3.879

Preacher, K., \& Kelley, K. (2011). Effect size measures for mediation models: Quantitative strategies for communicating indirect effects. Psychological Methods, 16(2), 93-115. doi: $10.1037 / \mathrm{a} 0022658$.

Primi, C., Morsanyi, K., \& Chiesi, F. (2014). Measuring the basics of probabilistic reasoning: The IRT-based construction of the probabilistic reasoning questionnaire. In K. Makar, B. de Sousa, \& R. Gould (Eds.), Sustainability in statistics education. Proceedings of the Ninth International Conference on Teaching Statistics (ICOTS9, July, 2014), Flagstaff, Arizona, USA. Voorburg, The Netherlands: International Statistical Institute.

[Online: http://icots.info/9/proceedings/pdfs/ICOTS9_C111_PRIMI.pdf ]

Rumsey, D. J. (2002). Statistical literacy as a goal for introductory statistics courses. Journal of Statistics Education, 10(3), 6-13.

[Online: http://ww2.amstat.org/publications/jse/v10n3/rumsey2.html ]

Schutz, P. A., Drogosz, L. M., White, V. E., \& Distefano, C. (1998). Prior knowledge, attitude, and strategy use in an introduction to statistics course. Learning and Individual Differences, 10(4), 291-308.

Tempelaar, D. T., van Der Loeff, S. S., \& Gijselaers, W. H. (2007). A structural equation model analyzing the relationship of students' attitudes toward statistics, prior reasoning abilities and course performance. Statistics Education Journal, 6(2), 78-102.

Tremblay, P. F., Gardner, R. C., \& Heipel, G. (2000). A model of the relationships among measures of affect, aptitude, and performance in introductory statistics. Canadian Journal of Behavioral Science, 32(1), 40-48.

Utts, J. (2003). What educated citizens should know about statistics and probability. The American Statistician, 57(2), 74-79.

Vanhoof, S., Sotos, A. E. C., Onghena, P., Verschaffel, L., Van Dooren, W., \& Van den Noortgate, W. (2006). Attitudes toward statistics and their relationship with short-and long-term exam results. Journal of Statistics Education, 14(3). [Online: http://ww2.amstat.org/publications/jse/v14n3/vanhoof.html ]

Vigil-Colet, A., Lorenzo-Seva, U., \& Condon, L. (2008). Development and validation of the Statistical Anxiety Scale. Psicothema, 20, 174-180. 
CATERINA PRIMI

NEUROFARBA - Section of Psychology

Via di S.Salvi 12 - Padiglione 26

50135 Florence, Italy 